\title{
La escalera de Witgenstein o Cómo dejar de rompernos la cabeza con la eficacia simbólica
}

\author{
FERNANDO GIOBELlina BRUMANA \\ Universidad de Cádiz
}

A Manuel Gutiérrez y su seminario, donde se hablaba de estas cosas

0.1. UN DRAMA TEÓRICO

"No nos quedan más que citas. La lengua es un sistema de citas"

J. L. BORGES

En diversas circunstancias, al enfrentarme a cuestiones como las de la hechicería o de la posesión, he tenido la evidencia de que la teoría tejida hasta el momento me dejaba sin cobertura alguna, como huérfano. Así lo he dado a entender en escritos en los que intentaba paliar mi perplejidad ante el desencuentro entre literatura y experiencia de campo o, las más de las veces, el desencuentro de la literatura consigo misma, su falta de consistencia. Ahora bien, si en un primer momento una carencia tal me resultó gravosa, más tarde me mostró sus beneficios. Tanto que, por último, he llegado a pensar que no vale la pena un trabajo que no desemboque en la diferencia, no denote una ausencia, no desafie lo ya establecido, no lo ponga en cuestión, en crisis. ¿Cómo se desarrolla más en vivo este drama?

En el campo, uno escribe. Es la "grafía" de la etnografía. Pero no escribe si antes no ha "leído". Leído no sólo, o no tanto, lo que de manera explícita es mensaje - lo expresado de una manera u otra por los agentes-, sino todo aquello que dice a pesar suyo, que dice sin decir, que dice - tal vezsólo para nosotros, observadores. En otras palabras, uno debe convertir en texto lo que, para ser eficaz, no se presenta a la luz como tal. Estas labores de "traducción", a poco que se las acometa, se muestran necesitadas de reglas, reglas que conforman lo que se puede llamar "teoría": el cañamazo sintáctico que subyace a la descripción que uno hace ${ }^{1}$.

1 Es necesario diferenciar esta manera de pensar la "teoría" - definida así como una suerte de gramática de un discurso disciplinario- de otra posible acepción suya 
Es entonces cuando uno cae en la cuenta de que ese cañamazo no está disponible, que nadie lo ha urdido. Pero esa falta —al menos es mi experiencia - sólo brilla cuando uno ya ha diseñado su perfil borroso como en una línea de puntos. ¿Qué plano discursivo, por encima del que uno está empleando, debería existir para legitimar tal descripción de espacios rituales o tal interpretación de un sistema adivinatorio, que las convirtiera en casos suyos? ¿Y qué diría? ¿Cómo se formula la Ley ${ }^{2}$ de la que lo que uno ha revelado sería un mero caso, pero un caso que exige serlo de una - alguna- Ley? Esto uno lo sabe como en sueños, si se me permite la comparación; la figura nunca está completa. La descripción o la interpretación se articula, pues, según una lógica cuya formulación está ausente: una teoría virtual. La "grafía" de uno vive a crédito de una construcción en ciernes. Veamos un ejemplo.

Cuando, en el prólogo a su colectánea de trabajos sobre hechicería y brujería, M. Douglas ${ }^{3}$ intentaba poner algún orden en ese campo de estudio, inauguraba una tentativa que, por fructífera que parezca, no tuvo continuidad ni sistematización en lugar alguno de su obra posterior, ni, que yo sepa, en la de nadie. La perspectiva implícita propuesta era la de tomar a las sociedades como espacios, topologías, cuya nudosidad interna al mismo tiempo es la conformación de la sociedad, tanto cuanto la manera en la que ésta es vista y actuada por los integrantes de tal conformación. De tal guisa, la creencia en brujas, o en todo otro peligro, como el de los leprosos a los que Douglas se refiere en un texto posterior, o el ya pretérito de los comunistas, despliega el mapa sobre el que se establecen distintas posiciones posibles: enemigos externos del grupo, alejados de él o infiltrados, desviacionistas peligrosos, enemigos internos alia-

que la concibe más bien como un contenido, un diagnóstico del estado del mundo. Es decir, modelo de discurso vs. modelo de urealidad». Esta segunda versión anhela ser en verdad fiel a su etimología, "theorein", visión de lo real. Pero, ¿cómo lo haría si - Witgenstein mediante- se necesitaría la totalidad del significante para dar cuenta del mundo? Como un mapa al estilo Borges, tan grande o mayor aún que el territorio representado, "teoría" - en este sentido- sería el conjunto de proposiciones que dan cuenta de los hechos atómicos. Lejos de tamaña desmesura mi requerimiento.

2 Que a nadie espante el uso de este término, al que le doy más que nada valor de norma de discurso. De todas maneras, cuando se apela a "ley", hay que hacerlo, y así lo hago, bajo la advocación a Witgenstein, quien casi al final del Tractatus logicophilosophicus (Madrid: Alianza, 1979 [1922]), parágrafos 6371-6372, hablaba así: ‘[...] la ilusión de que las llamadas leyes naturales sean la explicación de los fenómenos naturales. [...] Así los modernos confían en las leyes naturales como en algo inviolable, lo mismo que los antiguos en Dios y en el destinon.

3 Mary Douglas, "Introduction: Thirty Years after Witchcraft, Oracles and Magic", M. Douglas (ed.), Witchcraft. Confessions \& Accusations (London: Tavistock, 1976). 
dos con el exterior. Las formas mostradas, las combinaciones topológicas, ¿agotan el campo de posibilidades? No lo parece. Sin embargo, ¿dónde encontrar, cómo formular la totalidad de arreglos? ¿Existe acaso la posibilidad de establecer una geometría a priori, de la que estos ejemplos sean casos deducibles? $\mathrm{O}$, viendo las cosas desde otro ángulo, ¿existe la necesidad de una cobertura tal, un juego de legalidades que quizás no sea más rico que las anodinas leyes de la naturaleza social formuladas por Radcliffe-Brown? ¿No bastaría, por el contrario, quedarse con el recurso más o menos intuitivo de fuertes términos topológicos, como "centro", "periferia", "fronteras", etc.? ${ }^{4}$

Pensaba al comienzo, en la medida en que me formulaba a mí mismo la cuestión, que lo que se me representaba como agujero negro de teoría sólo podría ser resuelto en el cuadro de paradigmas aún inexistentes. Los Maestros - fuesen quienes fuesen los ilustres difuntos, o aún vivientes, a quienes adjudicase yo tal responsabilidad liminar (al menos: Durkheim, Mauss, Van Gennep, Freud, Saussure, Jacobson, Lévi-Strauss, Lacan)- habían llegado a un cierto punto, pero la disolución de mis perplejidades estaba más allá de esta frontera.

La idea que de esto me hago ahora es la inversa. No hay fronteras o, mejor, si las hay, encierran dentro de sí, como bolsones de resistencia, ciertas regiones intransitadas o mal transitadas. En otras palabras, todo el espacio de lo pensable está ya abierto. Todo objeto social - en el sentido más abarcador del término-, todo aquello que pueda ser enunciado en una proposición sociológica - también en el sentido más abarcador del término (es decir, hablando en instancias académico-administrativas, sociológica, antropológica, lingüistica y psicoanalítica) - se inscribe en ese espacio, ilimitado pero finito, como la cosmología contemporánea ve al Universo físico. Es evidente que no todo ha sido dicho, pero la lengua que permite cualquier formulación ya está urdida. Nuestros paradigmas son consistentes, si no quizás en el sentido duro de que no admitirían proposiciones que se contradijesen mutuamente, sí en el de que toda proposición posible es derivable de ellas. A partir de este cierre del campo, las posibilidades son, creo, dos: o partir hacia el escepticismo estetizante postmodernista o emprender la vía del conocimiento. Pero si se sigue la

4 En estas regiones del mundo, puede pensarse que, como en la Ithaca del poema de Cavafis, valen más los caminos que llevan que la meta: "¿l...] quién se atrevería a negar que, en nuestras disciplinas, las conclusiones valen esencialmente por el camino que a ellas conducen, las tesis propuestas por sus supuestos, las claves teóricas por las cerraduras que permiten abrir, las generalizaciones avanzadas por la exposición minuciosa de las singularidades que encierran?». G. LENCLUD, "Le monde selon Sahlins", Gradhiva, 9 (1991), p. 50. 
segunda alternativa, ¿de qué puede haber conocimiento?, ¿de qué puede haber ciencia?

\subsection{El ARGUMENTO}

Las reflexiones que aquí presento no están destinadas a fundamentar esta imagen o a responder a ciencia cierta los interrogantes abiertos, sino que, basadas en aquélla y con el fondo de éstos, vuelven sobre pasos ya dados para encontrar lo que estaba allí inadvertido. Reflexiones éstas que, para mí, sólo valen como la escalera con la que Witgenstein comparaba la labor de su Tractatus: un utensilio que no está más que para ser usado una única vez. Lugar de paso, no de estancia. Lugar que muestra su vacuidad cuando se le supera, que se desvanece. Si hay cuentas pendientes hay que cancelarlas de una vez por todas para abocarse a lo que en verdad interesa: construir una casa en la campiña austríaca, o producir conocimientos limitados de objetos delimitados. Desvelar figuras.

Decir las cosas de una vez, decir las cosas una vez, ¿cuánto texto ocupa? Tengo la impresión de que cuanto más central, más fructífera, más reveladora una idea, más breve su formulación. ¿Cuántas líneas necesitó Mauss para postular la noción de "hecho social total?? Comparemos esta virtud telegráfica con la abundancia minuciosa y cargante de los burócratas académicos - pienso en Parsons o en Merton- que normalizaron el pensamiento y la labor sociológicos décadas más tarde. El "Di tu palabra y rómpete" no sería apotegma desacertado para estas lides. De hecho, lo que quiero decir, lo que digo que está ya dicho, como horizonte último de la indagación sobre eficacia simbólica, puede condensarse en pocas líneas.

1. No nos es necesario a los antropólogos dilucidar los mecanismos neuro-vaya-a-saber-qué intervinientes. Nuestro cometido es otro.

2. Ese cometido es el de darnos cuenta de lo que ya nos hemos dado cuenta, es decir, de aquello sin lo que nuestra disciplina no sería tal. En otras palabras, abandonar el sentido común de nuestra cultura para asumir la disolución de eso que se nos dice que somos: "yo", "persona", en fin, la denominación que mejor entendamos que se ajusta a esa categoría, a ese construido.

3. Los "efectos corporales" —es decir, la productividad de la "eficacia simbólican- se inscriben en el juego entre sujeto y significación, en la misma medida en que el sujeto es un espacio abierto por la significación. La "eficacia simbólica" es el traslado al cuerpo de la significación que el cuerpo ya es; como enseñó Mauss, el cuerpo es un hecho -aconteci- 
miento y producto- de sociedad. En la pregunta por la "eficacia simbólica" se revela como en ningún otro sitio, como punto estratégico de mostración, el carácter fantasmático, especular y constituido, del sujeto. Tal pregunta se muestra, pues, no como una cuestión periférica o pintoresca en el campo de nuestra(s) disciplina(s), sino como indicador estratégico del nivel más fundamental de toda interrogación antropológica, su centro mismo. ¿Cuál es este centro, ese horizonte de inteligibilidad?

4. Éste: La prioridad de la significación sobre el sujeto, correlativa a su surgimiento abrupto y total. Tal irrupción es al mismo tiempo la de la separación entre significante y significado, y la que hay entre dos tipos de mujeres (instaurada por la prohibición del incesto). Esta doble y coincidente escisión (materialización del corte naturaleza/cultura), es el punto de partida de toda clasificación. Orden clasificatorio que abre con sus articulaciones el campo de lo sagrado. ¿Qué quiere esto decir?

5. Que la fuerza de la sociedad - lo sagrado de Durkheim- no se encuentra tanto en sus grandes movilizaciones extraordinarias, sino en la micro-costura y en la micro-repulsión implícitas en sus criterios clasificatorios. Lo sagrado, las operaciones que giran sobre ello, trabaja con estas valencias positivas y negativas. Hacer lo sagrado presente es fruto de la manipulación de las fronteras clasificatorias. Sus efectos - tanto los que hacen el orden de la sociedad, como los que hacen el orden del cuerpo- son producto de esa energía.

Las páginas que siguen recorren estas formulaciones de manera más detenida. No se trata, bueno es advertirlo, de un trayecto lineal, sino más bien del tipo al que Heidegger se refería con bolzweg, la pista trazada por el andar del leñador en el bosque, "chemin que ne mène nulle part" - dice la versión francesa-, "Senda perdida" - la española-; tal vez una referencia náutica hablase de "deriva". Las páginas que siguen van pues "a la deriva" entre los islotes detectados en la enumeración precedente. ¿Cabrá la posibilidad de una aforística antropológica?

\section{ACERCA DEL SUJETO}

\subsection{La bisteria}

El Verbo se hace carne, ése es el fenómeno con el que nos encontramos en las cuestiones que nos ocupan. Desde siempre, el pasaje entre lo corporal y lo simbólico ha producido entre los observadores que no se han negado a verlo muchas incomodidades. Uno de los procedimientos para superarlas ha sido remitir el asunto a la psicopatología: lo que ocu- 
rre es del dominio de la histeria. El propio Charcot, nos cuenta Freud ${ }^{5}$, veía en los fenómenos demoníacos históricos una raíz de esta naturale$\mathrm{za}^{6}$. Esta psiquiatrización de los fenómenos místicos no era, sin embargo, más que la reformulación de una tendencia muy antigua. En pleno período de la witch-craze, algunos de sus propios actores dieron una interpretación semejante. Los hombres de Estado y de Iglesia en España, a diferencia de lo que hicieron sus equivalentes en el resto de Europa, veían locura en las confesiones y auto-acusaciones de los supuestos hechiceros ${ }^{7}$. Como correlato de este saber, la Inquisición española - como ya he dicho, a contramano de la tendencia europea general- no quemó brujas; por el contrario, las protegió de las furias aldeanas. Sin embargo, lo que fue una visión esclarecida, propia de una nueva épistèmè, se convirtió con el tiempo en un escollo a la aproximación sociológica, no a una épistèmè más sino a la Ciencia — si se me permite-.

Las críticas a un escamoteo tal —realizadas por gentes como Bastide, Metraux, Leiris, Lévi-Strauss- fueron indispensables para sustentar los estudios llevados a cabo sobre estos problemas: no se trataba de una anormalidad clínica, sino de una normalidad culturalmente pautada y requerida. Sin embargo, al dar la espalda a la histeria no se caía en la cuenta de que se dejaba de lado algo que podría ayudar en mucho a encuadrar nuestro objeto. No, por cierto, porque sirva para algo poner el nombre "histérica" a la india cuna cuyo parto dificultoso es asistido por el canto del abisúa, o a cualquier otro caso descrito en tantas etnografías. Esta etiquetación es inútil o, para ser más preciso, anti-útil, no sólo, o no tanto, porque - como se dice en estas ocasiones- no se hace con ello más que desplazar la dificultad, sino porque echar mano de una categoría que en un caso así sólo puede ser abstracta (además, pero eso es otra cuestión, de extra-disciplinaria) nos ciega el acceso a la lógica específica del fenómeno, a su lógica cultural.

5 Obras Completas (Barcelona: Orbis, 1988 [1893]), vol. 1, p. 35.

6 "En realidad la Edad Media escogió ya esta solución (la hipótesis de una disociación de la conciencia) al admitir como causa de los fenómenos histéricos la posesión por el demonio. Todo se reduce a sustituir la terminología religiosa de aquella oscura y supersticiosa época por la científica de los tiempos presentes. Charcot [...] acudió al rico material de datos contenidos en los procesos por hechicería y posesión satánica, para demostrar que los fenómenos de las neurosis habían sido los mismos en todos los tiempos", Ibid.

7 C. GUILHEM, "La Inquisición y la devaluación del verbo femenino", B. Bennassar (ed.), Inquisición española: poder político y control social (Barcelona: Grijalbo, 1981), p. 207; G. HENNINGSEN, El abogado de las brujas. Brujería vasca e Inquisición española (Madrid: Alianza Universidad, 1983), p. 342. 
Tener a la histeria en cuenta no puede significar mantenerla en la reserva, como término descriptivo o heurístico para ser aplicado en caso de emergencia. Significa, sí, que lo que llamamos "eficacia simbólica" no necesita una propia legitimidad disciplinaria; no es cuestión de los antropólogos fotografiar por vez primera al monstruo del lago Ness. La construcción psicoanalítica de la histeria - de la histeria de conversión, por mor de exactitud- nos proporciona la evidencia clínica de que - uso una fórmula débil- cuerpo y signo no son realidades heterogéneas. El actual furor genético y neuroquímico concordará con ello, pero sólo para postular una línea de determinación no demasiado diferente, por cierto, a la que mantenía Lévi-Strauss en La pensée sauvage al anhelar la disolución de las ciencias humanas en las físico-químicas. La idea de que el mundo del símbolo es un efecto de la Naturaleza, sin embargo, tendría su baza máxima en la inexistencia de una lógica de aquél: un producto inerte de algo que ocurre en otro plano de realidad, el juego de sombras en las paredes de la caverna platónica.

Es esto, precisamente, lo contrario de lo que desde hace un siglo han mostrado aquellos que a estas cosas se dedican. Ahora bien, el tratamiento de la histeria tal vez sea el punto primero de la revelación de esta lógica del símbolo y de su potencia. Para eso, por cierto, había que pasar de Charcot a Freud, de la comprensión de la histeria como un desarreglo orgánico hereditario a su revelación como acontecimiento en el campo de la significación.

Ese trabajo, Freud no lo hizo en un día. Los primeros casos cuyos tratamientos registró nos lo muestran como a medio camino entre una visión y otra. Tocaba el cuerpo de la Sra. Emmy de N. con sus manos - los masajes que le aplicaba día a día- o con sus palabras - la sugestión hipnótica-, pero no a sus propias palabras, a las que aún no había aprendido del todo a escuchar, como reconocía en las notas a pie de página que agregó sólo cinco años más tarde ${ }^{8}$.

En lo que aquí me interesa: el psicoanálisis nació en el momento en que se intervino con símbolos sobre símbolos, teniendo no ya al cuerpo,

8 Unos ejemplos: S. FREUD, op. cit. [1895], notas 39, 45 y 46:

"Un simbolismo especial debió de hallarse enlazado aquí, sin duda, a la imagen del sapo; pero, desgraciadamente, no me ocupé de investigarlo".

‘[... Al día siguiente, una observación crítica de la enferma me hizo darme cuenta del error cometido al interrumpirlan.

«Desgraciadamente, no me ocupé, en este caso, de investigar la significación de la zoopsia, distinguiendo lo que la zoofobia tenía de horror primario, tal y como la presentan muchos neurópatas, desde la infancia, y lo que en ella había de simbolismon. 
sino al sujeto, a un sujeto segmentado, como diana de la operación ${ }^{9}$. Es así como de la secular pareja "cuerpo"/psique" se pasó a la de "sujeto"/ "Significación". No hay que dudar en subrayar que el psicoanálisis surgió a partir de la "lectura" de los síntomas histéricos; es decir, por la conversión del cuerpo del paciente histérico en texto. Una técnica médica se convertía así en teoría de la significación y del sujeto, de la primacía establecida entre ambos términos; pero lo hacía dentro del espíritu de la época, sólo en la medida en que tal teoría estaba siendo requerida, que estaba surgiendo y difundiéndose al mismo tiempo por todo el campo no sólo del discurso científico, sino de la revolucionaria producción cultural, de Schoenberg a Joyce, de Picasso a Breton ${ }^{10}$. Sólo en la medida, también o ante todo, en que la propia idea de Sujeto, tal como había sido constituido desde Descartes, se desplomaba.

\subsection{El cogito}

La filosofía fue el ámbito de discurso donde el Sujeto recibió la legitimidad del estatuto que había acumulado en la vida social y que ha mantenido durante siglos. Sin embargo, hasta ahora no ha dado cuenta de su deterioro. Con la salvedad de Nietszche y en menor medida de Heidegger, y dejando de lado las escuelas analíticas, que van por otro lado, la filosofía de nuestro siglo ha continuado en la senda cartesiana y la ha transitado - con Husserl y sus continuadores- hasta las últimas consecuencias. La oposición entre la fenomenología y lo que han ido desvelando los nuevos discursos disciplinarios se puede formular, entiendo, de la siguiente manera: o bien la significación es un acto intencional del sujeto (del sujeto trascendental, no de un sujeto empírico, claro está), o bien el sujeto es un efecto del significante, para retomar una fórmula lacaniana. O bien

9 Revelación de la ciencia que, como tantas otras, ha sido anticipada por las creencias y prácticas mística. En este caso, pienso en los dogon, de cuya visión de la palabra nos dice G. Calame-Griaule, Ethnologie et langage. La parole chez les Dogons (Paris: Institut d'Ethnologie, 1987 [1965]), p. 284: "Actuar sobre la palabra de alguien es actuar sobre todo su ser, sobre todos sus componentes físicos y espirituales".

10 El "flujo de la conciencia" inaugurado en el Ulysses documentó, por primera vez, lo lábil de la subjetividad. El uso desconcertante de la metaforización inaugurada por los surrealistas (de quienes tanto Lacan cuanto Lévi-Strauss estuvieron próximos) abrió una nueva forma de pensar —o, quizás, de des-pensar- que revelaba lazos insospechados por los que la significación se producía. Rupturas con el orden establecido en la (re-)presentación musical y pictórica realimentaron y se realimentaron de estas y otras rupturas. 
el sujeto constituye la significación, o bien el propio sujeto es el constituido por la significación. No se trata, por cierto, del estúpido juego del huevo y la gallina, o de una contradicción que se pueda saldar con una banalidad dialéctica.

Sartre, al tratar de superar en El Ser y la Nada lo que él llama "el escollo del solipsismo", dice algo así como que de la subjetividad se puede sacar cualquier cosa a condición de poder salir de ella. De esta manera, sintetizaba en gruesos trazos el punto de partida y la puerta de salida del pensamiento filosófico desde el siglo XvII hasta ahora. Cupo a la subjetividad la carga de sustentar la realidad del mundo, ya a través de un Dios que no podría engañarnos (Descartes), ya por la mirada del Otro (Sartre), ya por cualquier otro artilugio ontológico. En otros casos - Kant y, como caso extremo, Husserl- la única tarea en rigor admisible será la de describir los mecanismos por los que la realidad de la experiencia se constituye en el Sujeto. La res cogitans cartesiana - la cosa pensante, el Sujeto- se sobrepuso a la res extensa: la substancialidad pasó de ésta a aquélla. ¿Cuál fue el punto focal de esta inversión de veinte siglos de pensamiento? El que la evidencia se convirtiese en la piedra de toque de todo discurso, acontecimiento del orden de la historia social y cultural ${ }^{11}$. La subjetividad es el terreno único de la evidencia y la evidencia primera, tal el punto de partida de Descartes, es la de la propia subjetividad.

Cogito ergo sum es una de las expresiones latinas - sursum corda, alea jacta est, curriculum vitae, o babeas corpus son otras que ahora me vienen a la cabeza - que forman parte de nuestro cotidiano idiomático; tal es la fórmula con la que en la adolescencia se nos enseña a no dudar de la duda. Fórmula tan compacta como apócrifa, gestada a posteriori (jotro latinajo!) al volcar el texto francés a la lengua universal de la época, don Renato no la produjo de su pluma. Lo apócrifo de la fórmula potencia su compactibilidad; no es ya la transmisión de la translucidez de una experiencia liminar, sino, como la Gioconda reproducida en camisetas o en botes de mermelada, un objeto de cultura, una "cosa", hasta un emblema nacional.

Ese triste destino de fórmula divulgada del cogito, sin embargo, no traiciona su origen. La inmediatez de la existencia que así se expresa no es en verdad realidad primera. Lo que a Descartes se le ocultaba era, como la carta robada del cuento de Poe, lo más visible: cogito... o je pense, je

11 "La evidencia (en términos cartesianos: la idea clara y distinta) como contraseña y criterio distintivo de la verdad es fenómeno cultural constitutivo de una civilización en la cual el hombre es pensado y definido en términos de conciencia, de hegemonía del conocimiento sobre todas las otras instancias de la personalidad". G. VATtimo, La aventura de la diferencia (Barcelona: Edicions 62, 1986), p. 46. 
suis es, ante todo, un hecho de significación, es acto de lenguaje. Insisto: aunque hubiese algo así como una evidencia originaria de la propia existencia, el "cogito" no sería más que una re-presentación suya. El lenguaje no será una evidencia misma, pero es condición de evidencia, lo que ya la mediatiza, la corrompe, la amenaza de ficcionalidad, la des-evidencia. Derrida, un autor que siempre me ha resultado en extremo opaco, viene por una vez en mi auxilio. En nota a pie de página de su estudio sobre las Investigaciones lógicas de Husserl ${ }^{12}$ se nos permite leer, entre signos de interrogación, itálicas y múltiples comillas: «la percepción no existe o [...] lo que se llama percepción no es originario, y [...] todo 'comienza' por la 'representación'” ${ }^{13}$.

Quiero echar, por un momento, un cable a tierra etnográfica, a mi tierra etnográfica del Candomblé. Una frase del tipo ael sujeto es efecto del significante" tiene correlato empírico en la manera en la cual el fiel se descubre a sí mismo, se crea y se revela en el estereotipo de su dios tutelar: es a partir de la divinidad - es decir, del (de un) significantecomo él es él, que él es como él es. Lo tiene también en el acto de posesión, en el que el "caballo" debe aproximarse de manera asintótica, sin alcanzarlo plenamente nunca, al modelo de trance - un significanteque el culto le brinda y le impone. La acción adivinatoria produce asimismo al consultante, desde el saber sobre él que se articula en la boca del sacerdote — varios significantes superpuestos-, desde la disposición de las conchillas sagradas sobre el tablero -más significante-, desde los dioses que así se expresan - idem-. Todas las acciones a las que el novicio se ve sometido en su iniciación están destinadas a producir ciertas marcas y a borrar ciertas otras en el individuo que está (re)naciendo. “El sujeto es efecto del significante" es, pues, la manera más general y abstracta que tengo para hablar sobre las descripciones e interpretaciones que hago en el campo; si se quiere - aunque no sea obligatorio quererlo-, representa para mí su "explicación" como nivel teórico más abarcador, o quizás también la Ley, la Ley sobre cuya formulación me interrogaba al comienzo de este texto.

12 La voz y el fenómeno. Introducción al problema del signo en la fenomenología de Husserl (Barcelona: Pre-Textos, 1995 [1967]), p. 92, n. 3.

13 Páginas antes leemos: «Pero puesto que la posibilidad de constituir objetos ideales pertenece a la esencia de la conciencia, y estos objetos ideales son productos históricos, que no aparecen más que gracias a actos de creación o de enfoque, el elemento de la conciencia y el elemento del lenguaje serán cada vez más difíciles de discernir. Ahora bien, su indiscernibilidad, ¿no introducirá la no-presencia y la diferencia (la mediatez, el signo, el remitir, etc.), en el corazón de la presencia a sî?.. Idem, p. 52. 


\subsection{La máscara y la cara}

Los sociólogos no necesitan de tanto rodeo para saber que pre-judicativo no hay; la escuela del Année..., y más que nadie Marcel Mauss, lo vio con toda claridad desde un comienzo. Entre sí mismo y sí mismo, siempre está lo otro: la Sociedad, es decir, la arbitrariedad, la Significación. Desde las lágrimas vertidas en los funerales hasta la forma en que una tropa marcha, todo es dado, todo es previo a los agentes, todo es constringente. El propio cuerpo es un constructor social; las "técnicas corporales" encarnan - nunca mejor dicho- las "representaciones colectivas" de cada sociedad ${ }^{14}$.

El descubrimiento del Inconsciente por Freud, con los dos tópicos que lo formulaban, había hecho estallar la idea de un Sujeto unívoco, monolítico. Del otro lado del Atlántico, G. H. Mead lo había dotado de una diacronía evolutiva ( $\mathrm{Si}$ abandonamos la concepción de un alma substantiva dotada, desde el nacimiento, del yo del individuo..." ${ }^{15}$ ). Mauss, otra vuelta de tuerca, lo ha aplicado al programa de su escuela; la historia es ahora de las culturas. Un trabajo suyo nos pone en buena pista ${ }^{16}$.

El Sujeto (la persona, el moi - el "yo sustantivo", diríamos en una lengua como la nuestra que no hace la diferenciación francesa entre moi y je-) aparece en una secuencia milenaria de categorías, de representaciones colectivas, de ideas. No fantasmagorías, por cierto, en la medida en que las "ideas" de las que hablo, como la fe, mueven montañas y mucho más: producen la realidad. Ahora bien, la historia - lo ocurrido y lo narrado unidos - no es arbitraria; o, al menos, muestra en sus huellas su ley. De la máscara es de donde surge la categoría que nombra, condensa y constituye eso que está por detrás y por delante - nunca en el focodel Sujeto. "Persona", término latino universalizado por el derecho romano, es en su origen "máscara" (per-sonare: lo que permite la resonancia de la voz del actor): prosopon guarda en griego el mismo deslizamiento de significado; esta condensación es de primera importancia.

Máscaras hay muchas; tal multiplicidad tiene un grado cero, el de la máscara sin máscara, la pintura facial de los caduveo o de los maoríes, cuya absoluta geometricidad subraya su alineamiento con la Cultura para equilibrar su sujeción al natural elemento de la piel del rostro. En el otro

14 M. MAuss, Sociologie et antbropologie (Paris: PUF, 1950 [1935]), Sixième partie.

15 G. H. MEAD, Espíritu, persona y sociedad (Buenos Aires: Paidós, s. a. [1932]), p. 49.

16 M. MAuss, op. cit. [1938], Cinquième partie. 
extremo del espectro, las máscaras de los indios del noroeste americano cuyo análisis también debemos a Lévi-Strauss ${ }^{17}$. Este estudio, herencia de detenidos paseos por entre las vitrinas del Museo de Historia Natural de Nueva York a comienzos de los 40 , se desencadena desde la inquietud despertada por máscaras ahechas para ser llevadas delante del rostro, sin que el reverso, apenas cóncavo, case realmente con el modelo. [...] ¿Por qué esta forma inhabitual y tan mal adaptada a su función?." ${ }^{18}$. Esta tensión es producto de que la máscara debe conciliar reverso y anverso, sujeción al rostro y conformación de ese sobre-rostro, a la confluencia de múltiples planos de significación: mitos y leyendas sobre el origen de las máscaras, mitos reverberados en su confección, lugares sociales de sus portadores, ceremonias en las que son utilizadas, etc. Las máscaras, cada máscara, son nudos de redes de significación y de reciprocidad ${ }^{19}$; a partir del sistema en ciernes cobran todo su sentido. Ya alejándome de mi actual centro de interés: la vida de las máscaras llega a ser reproducción de la vida social hasta en el gesto de generación de Margen que las ha creado. Los mecanismos de inversión y carnavalización, para cuyo servicio se inventó la máscara y que escanden toda cultura, son re-producidos en algunos juegos de las máscaras; así, hay algunas de éstas que juegan papeles carnavalizantes y marginalizantes frente a otras "del centro" ${ }^{20}$.

El texto de Mauss nos provee de una ruta adicional. Ver que el Sujeto se hace, que es una categoría, es una cosa. Constatar que el Sujeto puede no hacerse a veces, o, mejor, que una cultura haga todo para que esa ilusión se deshaga, es otra. Esto es lo ocurrido en las antiguas civilizaciones de la India y de China: desde visiones religiosas — de religiones ateas, por cierto- ese acontecimiento que denominamos "individuo", "persona", "sujeto", es disuelto como un espejismo. La categoría $-\mathrm{O}$, mejor, esta anti-categoría- no se plasma en la organización del mundo, sino como lo que el mundo no es pero es para el mundo: margen presente en el centro. Pre-

17 La voie des masques (Paris: Plon, 1979). Y tantas otras máscaras, muchas ya citadas por Mauss. U otras más, como las de los dan de Costa de Marfil, la música de cuyos ceremoniales rituales, grabada hace varias décadas por investigadores franceses, estoy ahora escuchando (Ocora C 580048).

18 C. LÉvi-Strauss, op. cit., p. 13.

19 “[...] las máscaras, los privilegios que les son atribuidos, eran el trofeo de rivalidades y de intercambios, al mismo título que las mujeres, los nombres de personas y los productos alimentarios". C. LÉVI-STRAuss, op. cit., p. 42.

20 Un ejemplo: "En ciertos grupos del estuario (del río Frazer, costa oeste de Canadá), un payaso ceremonial que lleva una máscara algo diferente atacaba a las máscaras swaihwé a golpes de lanza como para perforarles los ojos, y los bailarines hacían como si los echasen". LÉvi-STrauss, op. cit., p. 20. 
sencia física, en los cuerpos de los monjes mendicantes: el despojamiento total ${ }^{21}$. Volver vida ejemplar la verdad del sujeto como espejismo; esa es la apuesta que los monjes viven por la disolución del yo, por la pérdida de sentido: el Nirvana. Pero esta nihilización de las clasificaciones es correlativa de algunos de los mecanismos clasificatorios más minuciosos, activos y marcadores de la vida social que se conocen - el sistema de castas indio y la identificación genealógica de los chinos-, como si un exceso de clasificación exigiese una contrapartida de fuerza semejante. Sea como sea, esa anticipación religiosa de lo que este siglo ha dado (aunque quizás mejor fuese decir "quitado") sobre el "Sujeto" es vista por Mauss como un caso entre tantos. Este "Sujeto" que nos empeñamos en ser es un invento nuestro, de nuestra Cultura.

La cara se termina endureciendo por la máscara; el sudor adhiere piel y materia muerta, las hace indiscernibles. La cara termina siendo lo que la máscara pide que sea. Es eso, y no otra cosa, lo que ocurre con la persona. Somos desde fuera. El Sujeto, Mauss así lo muestra, se hace a partir de nombres, de máscaras, de instrumentos jurídicos. Es decir, se hace desde la significación, o mejor desde significantes, si se quiere, desde el Significante. Hay Sujeto porque hay una barra que separa "Significante" de "significado". Esa prioridad lógica está inscrita en su propia constitución.

\section{El Big-BANG}

El descubrimiento fortuito realizado en 1965 por Arno Penzias y Robert W. Wilson de un fondo de radiación a $3^{\circ}$ absolutos desencadenó la carrera hacia la comprensión del origen del Universo ${ }^{22}$. Ha habido, nos dicen quienes están revestidos con autoridad para ello, un momento de equilibrio 0 que puede ser datado y con una evolución cronométricamente descrita, de una manera que a quienes trabajamos en ciencias light nos parece alucinante (por más que estos mismos días nos enteremos de que las últimas observaciones del Hubble acortan bastante estos cálculos). La exploración estelar realizada con diversos instrumentos permite ver, nos dicen también, estadios del Universo próximos a la explosión inicial que corroboran tales aseveraciones. No me resulta esto tan impresionante, sin

21 Despojamiento que coincide con el de nuestros místicos medievales, que forjaron una corriente "anti-yoica" en el cristianismo, presente aún en lugares comunes del tipo "No somos nada", con que a veces acompañamos nuestros pésames.

22 S. WEINBERG, Los tres primeros minutos del universo (Madrid: Alianza, 1994 [1977]), capítulo 3. 
embargo, como el hecho de que haya una huella del Origen —el fondo de radiación, un calor inexplicable - que permita su rastreo; que la forma en la que el Universo ha venido a la existencia tenga consecuencias que, miles de millones de años más tarde, posibiliten su reconstrucción teórica. Traigo a colación mis rudimentarias lecturas de textos de divulgación de ciencia dura porque supongo que hay otra huella y otro origen en juego. Es de esto de lo que quiero hablar ahora.

\subsection{La escisión original}

Mientras que la cuestión del origen del Universo, la pregunta cosmogónica, no había sido hasta hace pocas décadas una preocupación legítima para físicos, astrofísicos y especímenes equivalentes, sino más bien una inquietud mística, el origen del Homo sapiens sí ha tenido desde Darwin un venerable status científico, un camino ornado por los huesos fosilizados de las Lucys de la vida. Origen que, en sí mismo, no planteaba duda alguna. Cualquiera que fuese el cálculo del Carbono $14 \mathrm{u}$ otro método de datación, cualquiera que fuese la decisión de qué maxilar es ya humano y cuál aún no lo es, un hecho era incuestionable: hay hombres y hubo una época en la que no los había.

La hominización de los primates, el cómo, el cuándo, el dónde y el por qué de ese tránsito ha sido y sigue siendo objeto tanto de estudio cuanto de especulación. Como es obvio, un elemento clave de este proceso es la adquisición del lenguaje que, en general, se ha pensado como gradual. Ahora bien, ¿cómo entender esta gradualidad, sino como la aparición de significaciones atómicas que se enlazan en forma que alcanzan en algún momento la unidad de una lengua? ¿No se conjuga a la perfección esta postura con una concepción substancialista de Sujeto, esa misma cuya crisis acabamos de ver? Pensar en significaciones atómicas, es decir, significaciones cuyo valor se establece per se, de manera autónoma, implica a mi entender que deben derivarse de algo. ¿De dónde, sino del sujeto que les traspasaría su propia substancia?

Esta perspectiva, por otro lado, entra en contradicción con la doctrina sentada por F. de Saussure en su curso de Ginebra: la significación es un hecho de sistema; sólo existe desde y por éste. Una concepción lingüística tal da pie a pensar en un origen abrupto de la Lengua. Es el sistema, la articulación de todos los significantes, lo que se pone de una vez a ser; lo contrario es imposible. Aun sin echar mano de este razonamiento, Lévi-Strauss ${ }^{23}$ — con el antecedente de Sapir - postulaba la irrupción re-

23 "Introduction", a M. MAUss, Sociologie et anthropologie (Paris: PUF, 1950). 
pentina y conjunta de la significación: las cosas se pusieron a significar todas a la vez. Es decir, hubo significación (= la barra del S/s) donde antes ni siquiera no la había.

Vale la pena unir esta idea con otra también de Lévi-Strauss: la prohibición del incesto como pasaje de la Naturaleza a la Cultura, como origen de la Sociedad. ¿Qué es la prohibición del incesto? ¿Cuál es su efecto y sentido? La escisión entre dos tipos de mujeres (o de hombres, si se quiere ver la cuestión del otro lado); aquellas a quienes un individuo masculino determinado tiene acceso legítimo y aquellas a las que no lo tiene. La primera división social no fue entre hombres y mujeres ${ }^{24}$; esa es una división de naturaleza. La primera división "Social" es entre dos tipos de mujeres - $\mathrm{O}$, insisto en plan políticamente correcto, entre dos tipos de hombres. Quiero sugerir que ese corte es similar (¿metáfora, aliteración, a qué lingüistería acudir?) a la barra que separa Significado de Significante. En un caso como en el otro, es el Dos donde antes, en verdad, no se puede decir que hubiese Uno: en ambos hay la diferencia.

Si el Dos es efecto de esta doble ruptura originaria, es a partir de él desde donde se despliega todo juego clasificatorio: el dualismo de equilibrio que necesita mantenerse binario (como los casos estudiados por Needham y su entorno), el dualismo mesiánico que quiere retornar a la confusión de oro del Uno - sea etnia, nación, clase, fe-, las diversas ternas (la de mediación, la sacada a la luz por Propp en los cuentos fantásticos rusos, etc.), el polinomio totémico y el de castas. La intuición durkheimiana sobre la existencia de un eje "organización social/principio clasificatorio", bajo esta perspectiva, se confirma al mismo tiempo que se reformula.

Las clasificaciones son sociales y no hay sociedad sin clasificación, pero queda ya atrás la idea de determinación unilineal por la que los procedimientos clasificatorios - o mejor, sus resultados- no son más que la transposición ideal de una forma de vivir social, como Durkheim intentó mostrar con esfuerzo. La clasificación, entonces, es social porque (significa que) la sociedad, la cultura, no ha podido surgir más que de $-\mathrm{y}$ no puede mantenerse más que en- un juego de inclusiones y exclusiones. Toda

24 Por más que, como Durkheim sostiene en La división del trabajo social, sea la primera división de trabajo. Pero esta especialización por género, si no parece demasiado sexista decirlo de esta manera, atiende en primer lugar a una diferenciación de naturaleza y proviene de otros primates antecesores. Ya entre los babuinos y más tarde entre los cazadores proto-homínidos se dio "la necesidad de una división del trabajo por razón del sexo [...]: los machos deben procurar la carne y las hembras las verduras". R. FOX, La roja lámpara del incesto. Investigaciones de los orígenes de la mente y la sociedad (México: FCE, 1990), p. 188. 
sociedad, a su vez, se despliega en sistemas clasificatorios cuyas lógicas son limitadas - no todo puede ocurrir, o mejor, puede ocurrir muy pocoy preestablecidas: los binarismos, ternarismos y polinomismos que antes he mencionado. Una perspectiva tal me podría llevar a sostener que sí hay (que puede haber, que hay que apostar porque haya) conocimiento y Ciencia en Antropología: la de las topologías simbólicas subyacentes a la realidad social.

\subsection{Ausencia y significación}

Pero volvamos al origen del lenguaje. Si éste ha sido gradual para la mayoría de quienes se han enfrentado con la cuestión, para quienes suponen - los mismos u otros- que tras un idioma único hubo su pérdida y confusión, su multiplicación en lenguas diferentes, ésta fue fulminante. Hablo de Babel. El enciclopedista que tomó sobre sí la entrada "Lengua" nos lo dice: “Si esta confusión del lenguaje primitivo no hubiera sido súbita, ¿cómo habría podido sorprender a los hombres hasta el punto de reconocerla como un monumento duradero, como el nombre que le fue dado a esa misma ciudad, Babel?, ${ }^{25}$.

Un psicoanalista de sintonía lacaniana, Pérez Peña ${ }^{26}$, encara Babel desde la carta del Tarot llamada "La Casa de Dios", una torre rota por un rayo. ¿Qué indica Babel? Una castración, castración segunda; la primera ha sido la de la prohibición del incesto. Castración, palabra que aunque nos suene tan mal a los ajenos a la terminología psicoanalítica en verdad no indica a mi entender otra cosa que la fundación de un plano que deja los testículos fuera: el plano de lo simbólico, de la Cultura. Babel, pues, es uun signo de la castración en el sujeto humano, porque también en él su lenguaje se torna equívoco, ya que con una palabra puede señalar muchas cosas y no quedan señaladas unívocamenten. Russell y sus allegados vieron con claridad que todo lenguaje natural encerraba equivocidad; sólo un lenguaje artificial podría llegar a ser unívoco.

La equivocidad - esto ya no es Russell - no es otra cosa que la primacía del Significante sobre el significado, el hecho de que el significado no sea - como parece que Saussure suponía- una instancia previa al Significante, y que éste sea, más bien, un mero medio de comunicación suyo, sino que el Significante constituye y recorta su significado. ¿Cómo

25 B.E.R.M., "La Enciclopedia: artículo 'Lengua'", apéndice a J. J. RousSEAU, Ensayo sobre el origen de las lenguas (Madrid: Akal, 1980 [1784]), p. 150.

26 Espacio de configuración de lo psíquico (Buenos Aires: El Cid, 1982), p. 66. 
no habría de ser Babel un monumento duradero si marca en el plano del mito el momento en el que, en realidad, ha habido significación primera, es decir, en el que un Significante podía producir diferentes efectos de sentido, y que los mismos sentidos pudieran ser efecto de Significantes diferentes?

Ahora bien, si Babel es monumento de una frontera, ¿qué habría de haber antes? Veamos cómo se lo representa un teólogo loco, personaje de la trilogía de Nueva York, de Paul Auster:

La única tarea de Adán en el Edén había sido inventar el lenguaje, ponerle nombre a cada criatura y cada cosa. En aquel estado de inocencia, su lengua había ido derecha al corazón del mundo. Sus palabras no habían sido simplemente añadidas a las cosas que veía, sino que revelaban su esencia, literalmente les daban vida. Una cosa y su nombre eran intercambiables. Después de la caída, esto ya no era cierto. Los nombres se separaron de las cosas; las palabras degeneraron en una colección de signos arbitrarios; el lenguaje quedó apartado de Dios. [...] En otras palabras, la torre de babel representa la última imagen antes del verdadero comienzo del mundo ${ }^{27}$.

27 P. AuSTER, La ciudad de cristal (Barcelona: Anagrama, 1997), p. 57. En el Cratilo de Platón (Paris: Garnier-Flamarion, 1967), tal vez la primera reflexión sobre el origen del Lenguaje, encontramos una concepción no muy lejana. No se sabe a ciencia cierta -nos dice el traductor francés E. Chambry- si se trata un texto "serio" o una farsa paródica de las invenciones de los sofistas; es decir, no sabemos si es un texto del mismo nivel del de Auster o del de su personaje demencial. De todas maneras, en él vemos la esencia de las cosas en la raíz de los vocablos que las mientan. Habla Sócrates:

"Cratilo tiene pues razón de decir que los nombres de las cosas derivan de su naturaleza, y que no todo hombre es un artesano de nombres, sino sólo aquel que, con los ojos fijos sobre el nombre natural de cada objeto, es capaz de incorporar su forma en las letras y las sílabas" (390d).

Sigue a esta declaración una multitud de explicaciones etimológicas, muchas veces extravagantes, que buscan fundamentar lo apropiado de cada nombre. Así "héroe" permite ver el origen de estos seres en el amor (eros) entre divinidades y humanos; en "hombre" (anthrôpos) subyace la condición de aquel que "contempla lo que ha visto" (anathrôn ha opôpé); los propios dioses (theoi) han sido designados así por la "facultad natural de correr" (théin) (397c). Platón, o mejor, su personaje Sócrates, no puede dejar de desesperar de esta vía; si no, no se explicaría que la segunda parte del diálogo se dedique a acumular argumentos contrarios a la tesis de Cratilo. ¿Por qué? Porque, como dice LACAN, El seminario de Jacques Lacan. Libro 20. Aún (Buenos Aires: Paidós, 1989 [1972]), p. 40, nunca se sale de un juego referencial entre significantes: lo que el texto refleja en las diversas explicaciones que se dan de algún término - Chronos- o en el reconocimiento de que los nombres dados a los dioses por los hombres no recogen más que "las opiniones que (los hombres) debieron tener cuando se los dieron" (400e). 
Tal lengua edénica es lo que es: si idea colectiva, mito; si idea individual, como en la novela citada, delirio psicótico ${ }^{28}$. Aun en el bien posible supuesto de que haya habido alguna vez una única lengua, su arbitrariedad habrá sido tanta como la de cualquiera de las tantas lenguas que los hombres hablan hoy en día: la equivocidad encarna dentro de cada una lo mismo que la diferencia puesta en juego por la traducción ${ }^{29}$. La significación, al igual que el sujeto, sólo es tal por la ausencia.

"Somos nuestras ausencias", decía yo en un texto anterior; el sujeto no está presente a sí mismo - como la metafísica cartesiana ha querido-, sino radicalmente ausente a sí mismo. No soy transparente a mí mismo, soy opaco. "Puedo saber lo que piensa el otro, no lo que yo pienso", dice Witgenstein en las Investigaciones filosóficas ${ }^{30}$. El gnosi seautón - conócete a ti mismo- helénico es una tarea infinita o imposible, un engañabobos o la temprana certeza de que una auto-aprehensión nada tiene de inmediato. Este corte de uno con uno es correlativo a que (producto de que) la significación misma sea, Lacan dixit, "la presencia en la ausencia y la ausencia en la presencia.. En el origen del signo, dice Derrida ${ }^{31}$, está nuestra ausencia, nuestra relación con la muerte. Diría yo: en la raíz de nuestra ausencia está el signo.

28 Parece que Freud - no he podido encontrar dónde- pensaba en una lengua primera, pura expresión del Inconsciente. Tal es, al menos, la impresión que me deja lo que dice Julia KRISTEVA, Le langage, cet inconnu. Une initiation à la linguistique (Paris: Points, 1981 [1969]), p. 270: "Sin llegar a la hipótesis que supone que 'la lengua primitiva' se conformaría a las leyes del inconsciente - hipótesis que el lingüista no admite y que ninguna lengua antigua o primitiva parece confirmar en el estado actual del conocimiento-, parecería más pertinente buscar las reglas lógicas descubiertas por Freud en la organización de ciertos sistemas significantes que son tipos de lenguajes por sí mismos".

29 Derrida también habla, y en varias ocasiones, de Babel. Vale la pena, tal vez, ver una síntesis de por dónde van sus tiros, en palabras de un coautor suyo. G. Bennington y J. DeRrida, Jacques Derrida (Madrid: Cátedra, 1994), p. 191: "Al gritar su nombre, Babel, Dios exige una traducción que no se consigue sino produciendo precisamente la confusión".

30 Frase que Manuel Gutiérrez Estévez nos recuerda en el epígrafe de un texto suyo (De la conversación yucateca al diálogo cristiano y viceversa") de donde lo he robado.

31 La voz y el fenómeno. Introducción al problema del signo en la fenomenología de Husserl (Valencia: Pre-Textos, 1995), p. 104. 


\section{Inciso: pensando en la vagina}

He hablado del origen del universo, ¿por qué no del "Origen del Mundo", el cuadro de Courbet ${ }^{32}$ ? En esta pintura asistimos a la íntima desnudez de una mujer sobre una cama deshecha; como centro, su sexo entreabierto. El sesgo con que éste se ofrece a la vista, sin embargo, lo revela menos propicio para el coito que para la significación. Significación indicada en el título del cuadro, sí, pero también reflejada de una manera más esencial.

Me costaría no ver en la oblicuidad de ese sexo, la misma inclinación del signo gráfico "/n, la barra con la que los lingüistas indican el hecho de la significación $\mathrm{S} / \mathrm{s}$. Es cierto que una metaforización tal, por más que me resulte sugerente, es tan arbitraria cuanto anacrónica; no obstante, trasluce una verdad. En efecto, qué mayor metáfora de la significación puede ofrecer un cuerpo que un agujero - $-\mathrm{y}$ ese preciso agujero-, lo que es por no ser: una presencia que se revela como ausencia, una ausencia que se revela como presencia. A este sexo de paradoja y esfumación se corresponde el de la ineludible y mera presencia: el Falo, lo que es por ser. En el ámbito de discurso lacaniano, o mejor en una traducción al lévi-straussiano de una cuestión lacaniana, se trata de una masa que torna no euclideo — curvo, cerrado sobre sí mismo- el espacio mítico en el que se da el pasaje de significación entre diversos códigos - vegetal, animal, sexual, astronómico, etc.-: un significante primordial, un centro de gravedad. El mundo de la significación se despliega en torno a este eje, gira a su alrededor. Pero esto es otra historia.

Uno es ausente a sí mismo. No hay substancia alguna a la que agarrarse; el único recurso es que esa ausencia se niegue. Ausencia de la ausencia, ese es el propósito tras el que van los mecanismos que hacen que el sujeto sea... algo. Sujeto, para no ir más lejos. Justo mediante la apariencia de lo contrario, la identidad produce entidad. Proposición que en realidad encierra: los procesos de identificación hacen que uno sea. La identificación me convierte en uno, sólo a costa de ser otro, sólo a costa de que no haya un uno que sea. Esta insubstancialidad es la misma de la de la significación y le proviene de ella. La significación no tiene antecedente; en nada se basa y viene de la nada. La significación ha acontecido, como ha acontecido el universo. Le ha caído encima a una especie

32 Cuadro que tiene su historia. Pintado en 1866 para el embajador turco en Francia, fue comprado por Lacan (i!) en los años 50. Como nos cuenta Elizabeth Roudinesco en su biografía, lo guardaba disimulado bajo una representación abstracta encargada por su mujer a André Masson. ¡Vaya con los juegos de espejos! 
que había abandonado a dos pies la selva por la sabana, que había aumentado su capacidad craneana, que había llegado a determinado plano de sociabilidad. Como dice La Biblia, en el principio era el Verbo ${ }^{33}$.

\section{SOBRE LO SAGRADO}

"La sociedad se adora a sí misma, a su propia fuerza, en la figura de sus dioses". "Lo sagrado es cuestión de contagio, de contaminación, de cosas que se pueden tocar y de cosas que no se pueden tocar". No creo falsear la doctrina de Durkheim si afirmo que esos dos - hay un tercero, ya veremos- son sus postulados centrales en la dilucidación de lo religioso. El sociologismo de la primera aserción y el supuesto emotivismo de la segunda irritaron a Lévi-Strauss. No obstante, no son tan lejanas a sus propias enseñanzas; o al menos, no tan difíciles de conciliar. Por otra parte, estas dos afirmaciones dan la base de todo lo que pueda decirse sobre la región de lo sagrado, el terreno en el que se desenvuelve la "eficacia simbólica". Base que, para ser operativa, debe ver completada su figura con otra afirmación: "El rito organiza el mundo del fiel”. Entremos en este triángulo por el último de sus vértices. ¿Qué pasa con el ritual?

\subsection{La marca ritual}

Recordemos la escena de la rendición argentina en el conflicto de las Malvinas. En Puerto Stanley, cara a cara, dos hombres. Uno, el jefe britá-

33 No me resigno a ignorar el ingenioso y atrevido libro de Robin Fox, La roja lámpara del incesto (México: FCE, 1990), que fusiona Darwin, Marx, Freud y LéviStrauss, en una interrogación sobre el origen del hombre. Hay aquí también huella, pero esta vez es neurogenética: el cerebro humano guarda como información lo que Freud vio como la muerte del padre en la horda primitiva. "[...] llevamos a la sociedad dentro de nuestra mente, tal como lo vio Durkheim, pero no sólo porque la incorporemos por medio de la socialización: está en nosotros desde el principio" (p. 253). La culpa es, pues, nuestro lote, lo que nos caracteriza como especie y lo que explica nuestro origen. Fox oculta su voz bajo un remedo de la de Freud para formular lo que me parece el centro de su argumento: “[...] toda la fuerza de la lógica de nuestras observaciones de neuróticos, de niños y salvajes, por no mencionar la culpa humana y todo el aparato de la religión y de la política, nos obliga a concluir que algo muy drástico ocurrió en la evolución del hombre, que desembocó en un ser así, tan obsesionado por estas extrañas fantasías, y tan compulsivo por razón de ellas mismas" (pp. 80-81).

Sí, pero, ¿cómo pensar en "culpa" sin significación anterior a ella? 
nico, con ropa de combate, con barba de varios días, seguramente sudoroso y maloliente. El jefe argentino, por el contrario, lucía uniforme de gala y su afeitado era tan impecable como su peinado, y éste tan brillante como sus lustrosos zapatos. Para el primero, me permito imaginar, el acto de rendición no era más que la conclusión técnica de una serie de actos técnicos que lo habían llevado, a la cabeza de sus hombres, de la playa de desembarco hasta el cuartel general argentino, por muchos kilómetros de tierras intransitables bajo fuego enemigo. Acababa así con la resistencia del contrincante, lo desarmaba, lo hacía cautivo. Como dice Bernanos en su Cementerios bajo la luna: la guerra es tratar de meter metal en los cuerpos de otros hombres, una cuestión de cosas.

Para el segundo jefe militar, en este caso la presunción es más fuerte, se trataba de un acto ritual. En efecto, no había mostrado virtud castrense en el campo de batalla; para un general argentino acostumbrado a torturar cuerpos atados a una mesa y a mandar el producto de sus robos a bancos suizos, el silbido de las balas es un sonido desconocido; ya Borges lo dijo por esas fechas. Pero, si no había combatido como un soldado, tenía aún la posibilidad de rendirse como tal. La virtud castrense sólo podía exhibirse en las formas: la acción ritual era, pues, indispensable, aunque, por cierto, no es frecuente que los rituales sean correlativos de la maldad y la cobardía.

Ahora bien, ¿qué es lo que hace ritual al ritual? ¿su contenido? En principio, no pareciera que lo fuese, si pensamos que vemos ritual en acontecimientos tan lejanos uno al otro como una junta de accionistas, una boda, unas oposiciones para funcionario público o la consagración de la hostia en nuestras misas católicas. ¿Su función? ¿cuál sería? Es clara la respuesta durkheimiana, tanto del maestro como de toda su cohorte: la función del ritual es el mantenimiento de la cohesión social. No es necesario para sostener esto siquiera la suposición de una astucia de la "razón social", un resorte que actúe con independencia de la voluntad y de la conciencia de los agentes. Estos, por el contrario, la mayoría o quizás la totalidad de las veces son conscientes del mecanismo en juego, muchas veces lo han puesto ellos mismos en marcha. Recordemos las carcajadas con que los bosquimanos !kung recibieron la pregunta del antropólogo de turno sobre si creían que la lluvia que estaba cayendo era, en verdad, producto del ritual propiciatorio al que acababa de asistir ${ }^{34}$. "Cómo podemos ser tan ingenuos con las creencias de los demás?", se termina preguntando la autora.

Pero, ¿acaso no es también ingenuo suponer que el hecho de que la interpretación del observador y la de los observados coincida es garantía

\footnotetext{
34 M. DOUglas, Purity and Danger (London: Paul \& Kegan, 1966), cap. 4.
} 
de su idoneidad? No es que piense yo que el ritual no cumpla funciones homeostáticas en el sistema, que no opere a favor del mantenimiento del sistema. Resulta obvio que los casos descritos y analizados durante décadas por los antropólogos británicos se ajustan a este esquema. Pero, el conjunto del universo ritual, ¿está cubierto por el modelo que responde a estos casos?

Mi primera y lógica tentación es acudir a los ceremoniales, a los que he dedicado mis investigaciones de campo en Brasil, destinados a provocar efectos materiales y espirituales en ciertas personas. Efectos positivos, a veces; otras, negativos. Acciones también destinadas a que alguien (el cliente, $\mathrm{o}$ aquel a quien el cliente pretende favorecer) cure de una enfermedad, encuentre empleo o compañero/a sentimental. Acciones destinadas a que alguien (esta vez, el enemigo) pierda la salud, el trabajo, el amor, a veces la propia vida. Es bien sabido que la separación entre eso que llaman la magia "blanca" y la otra se difumina entre los dedos, que el anti-hechicero no es otro que el hechicero. Pero no me dirijo ahora en esa dirección. Ambas acciones místicas son, por lo que aquí importa, idénticas.

En efecto, estas prácticas están tejidas como breves narraciones que, con mecanismos metafóricos y metonímicos, cuentan lo que debe ocurrir al objeto de la acción mística. Aunque sean espectaculares, además, estas acciones no tienen en el espectáculo su objetivo, sino un medio para otros fines. No pienso ya en las operaciones de hechicería, cuya no publicidad, su ocultación, forma parte de la acción y coadyuvan a su eficacia. Pienso en un caso extremo de no ocultación, de publicidad y hasta de teatralidad: las manifestaciones mediúmnicas descritas por Leiris en Etiopía, Metraux en Haití o por mí mismo en Brasil. Por más vital y pleno sensorialmente que en este caso sea el espectáculo, no es su razón primera; lo es el carácter terapéutico, para el agente o los eventuales clientes, que tiene la incorporación de ciertos espíritus o la obligación que los fieles del culto dan a una cierta periodicidad de la presencia "en la tierra" de las entidades místicas con las que han sellado pactos de protección y cuidado, a riesgo de consecuencias negativas. La relación con lo sagrado, en estos casos, tiene su órgano de pertinencia en el cuerpo. En estos ceremoniales, la función reguladora social no es tan fácil de reconocer. No obstante, I. Lewis ${ }^{35}$, en el sendero abierto por Gluckman con sus arituales de rebelión", los absorbe en el marco funcionalista con la hipótesis de que la posesión, típica de cultos periféricos, es una protesta simbólica ante la marginación de los sectores sociales que alimentan esos cultos. La

35 Extase religioso (Sâo Paulo: Perspectivas, 1977). 
insuficiencia de esta teoría es una repetición monótona de lo que siempre se puede decir de las explicaciones de la escuela británica: ¿por qué tal conflicto social se expresa en este registro y no en otro? En lo que ahora nos atañe: ¿protesta simbólica? Sí, ¿pero es eso todo? En estos casos, como en aquellos en los que la reproducción del orden social es más evidente, otra vez, ¿es eso todo o hay además otra cosa, menos visible para agentes e investigadores, pero al mismo tiempo más obvia? Sigamos con otro ejemplo militar.

Claude Roi, un francés de izquierdas con pasado militar, visitó China no demasiado después de la victoria maoísta. Lo primero que le sorprendió, y así lo contaba en su Claves para China, fue que los soldados que vio en el aeropuerto no parecían tales. Uniformes poco cuidados se unían a una marcha sin paso de marcha. Quienes hayan visto por TV a los soldados de Pekín que llegaban a Hong Kong las vísperas del final de la administración inglesa no han podido obtener una imagen más opuesta: impecables hombres en posición de firme, inmóviles durante horas en los camiones que los transportaban. Ninguna necesidad material detrás de ese espectáculo, sólo el propio espectáculo, pero no tanto algo para ver, cuanto más bien algo a lo que asistir como acto simbólico, como algo significativo.

Ritual es precisamente eso: una señal de significación. "Esto está para significar", eso dice el ritual. Pero, ¿significar el qué? De hecho, cada rito carga en sí significaciones particulares, emplea pre-textos específicos; preguntar por la significancia ritual apunta al efecto de sentido suplementario $\longrightarrow$ o primero- que tiene el significar esas particularidades por medio ritual, o mejor, hacer ritual con pre-textos particulares. ¿Cuál es este efecto de sentido? Veamos un último ejemplo militar.

El desfile de tropas, de cualquier tropa, que Mauss recordaba en su texto sobre las técnicas corporales, se basa en imponer a aquéllas, al desempeño de sus cuerpos, un estilo diferenciado al habitual. Aunque en este ejemplo, dicho sea de paso, la diferenciación es doble: el paso de un ejército debe destacarse al mismo tiempo de los pasos de otros ejércitos (paso de oca prusiano, carrerilla de los bersaglieri italianos, etc.) ${ }^{36} \mathrm{y}$ de la manera en que sus componentes caminan en el día a día. Lo que aquí importa: el círculo de tiza que separa de lo cotidiano, eso es "ritual".

36 Los distintos pasos de marcha nacionales operan como emblemas de unidades de un sistema polinómico-totémico, es decir de unidades del mismo rango, equivalentes, en ese sentido, a los cánticos de hinchadas de fútbol o a las danzas diferenciales de los dioses del Candomblé o de la santería cubana. No es tema de este texto las formas en que se articula el espacio dentro de lo cerrado por el círculo de tiza del que hablo en la próxima frase. 


\subsection{Ritual y sistema clasificatorio}

Lo cotidiano es la norma, la estructura - en el sentido que le da $\mathrm{M}$. Douglas-, el sistema. El ritual abre un agujero en la uniformidad de la vida social: pone al margen, liminariza - si un verbo tan horrible existe-, aunque a veces sea el propio centro lo puesto al margen - lo liminarizado, con perdón-, como en el caso de los casamientos de las Infantas españolas o los funerales de Lady Di. Carnaval, Semana santa y día de la patria los casos rituales tomados por Da Matta ${ }^{37}$ - dan aire, dan juego a la vida de la sociedad produciendo margen. Pero eso no es todo.

No puedo recordar si era o no Leach quien clasificaba los rituales en "expresivos" y "productivos", para marcar la distancia entre, por ejemplo, la ceremonia !kung a la que se refería M.Douglas y la ordalía de pollos zande. De todos modos, la realidad es - como se decía hace mucho tiempo- "dialéctica": la expresividad de los ritos expresivos es productiva, produce algo -en este caso, al menos, cohesión social-: a su vez, la productividad de los productivos es expresiva, expresa algo -al menos aquello que sirva al observador para interpretarlos-. En un caso, se trata de operaciones que ponen la acción al servicio de la significación; en el otro, emplean la significación con fines instrumentales. En ambos se trata de juegos con los poderes del entramado clasificatorio, donde todavía yace el sagrado-durkheimiano (remozado).

La fuerza de la sociedad no está tanto, como sostenía Durkheim, en el fervor multiplicado del intichuma, la festividad anual que reúne a los clanes de la tribu australiana para el sacrificio de sus especies totémicas, medio de conservación de la fertilidad natural y de la sociabilidad humana. La fuerza de la sociedad no es tanto el poder macroscópico de su condensación en la conciencia colectiva de sus miembros: es más bien el cemento intersticial de la cohesión del mundo; se manifiesta antes y ocurre primordialmente en un plano más microscópico y permanente, menos espectacular, hasta invisible. Es el plano en el que se producen, por ejemplo, las prohibiciones alimentarias bíblicas, tan bien interpretadas por $\mathrm{M}$. Douglas, o cualquier otro tipo de tabú. Es el plano en el que las mujeres no pueden entrar en las bodegas jerezanas a la hora en que la uva es prensada, en el que la mano izquierda es izquierda, o en el que hay que ir de chaqueta y corbata a una entrevista de trabajo.

Lo sagrado, pues, anida y se manifiesta en la clasificación. La manipulación de ésta es el ritual, sea para subrayarla, sea para invertirla. El po-

37 Carnavais, malandros e heróis (Rio de Janerio: Zahar, 1980). 
der del ritual, tanto en su faz "expresiva" cuanto en la "productiva", proviene de la fuerza que une las cosas que el ritual separa, o de la que separa las cosas que el ritual une.

Lo sagrado es un acontecimiento de la significación. Más aún, es la propia significación ante sí misma. Si se me apura, es la propia barra del $\mathrm{S} / \mathrm{s}$. Es desde este núcleo duro de la realidad que somos, desde este BigBang que nos produjo, desde este pasaje de la Naturaleza a la Cultura, desde la hominización de la Humanidad — si nos ponemos muy cursis-, desde donde se despliega la lógica clasificatoria $(2,3, n>3)$ por donde discurre nuestra vida social. Lo sagrado es la fuerza subatómica que hace que algunas cosas vayan juntas y otras vayan separadas. Lo sagrado aparece, opera y produce efectos en la inversión del sentido de esas valencias. Lo sagrado es carnavalizante. Obscuro espejo invertido.

\section{EN FIN}

Sujeto y sagrado provienen del Big Bang de la significación, del erguimiento de "/, lo que nada tendría que sorprendernos. Algo de esto está ya intuido en la idea dogon de "palabra", en el Verbo bíblico, en el pensamiento romántico, en Heidegger, en los budistas. Pero toda la fuerza de la cultura está puesta para ocultarlo. Sin el espejismo resultante, no hay sociedad posible. Ese es el suelo de la "real ilusión" de la que hablaba Mauss.

Dentro de este cuadro, la "eficacia simbólica" es la prueba del nueve del pensamiento sociológico: el punto en el que se torna transitable a la investigación la vía que debe ser invisible para que haya cultura, aquella que une las formas y peripecias de las relaciones entre los hombres - por un lado- y sus cuerpos - por el otro-.

Pues eso. "Y no tenemos nada que añadir", como decía una propaganda de conservas de pescado. 
La pregunta por la "eficacia simbólica" revela como en ningún otro sitio el carácter fantasmático, especular, constituido, del sujeto. Tal pregunta se muestra, pues, no como una cuestión periférica o pintoresca en el campo de nuestra(s) disciplina(s), sino como indicador estratégico del nivel más fundante de toda interrogación antropológica, su centro mismo. Esto es, la prioridad de la significación sobre el sujeto, correlativa a su surgimiento abrupto y total. Tal irrupción es al mismo tiempo la de la separación entre significante y significado, y entre dos tipos de mujeres (instaurada por la prohibición del incesto). Esta doble y coincidente escisión (materialización del corte Naturaleza/Cultura), es el punto de partida de toda clasificación. Orden clasificatorio que abre con sus articulaciones el campo de lo sagrado.

An inquiry about "symbolic efficacy" reveals the phantom, reflected on, constitued character of the subject. This is not a peripheral, picturesque matter in our field(s), but rather a strategic indicator of the most basic level in any anthropological scrutiny; i.e., an indicator of anthropology's core: of the priority of meaning over subject, which correlates with the abrupt, total emergence of meaning. Such emergence is, at the same time, that of the separation between the signifier and the signified, as well as the separation between two types of women as established by the prohibition of incest. This twofold and coincidental split (an embodiment of the opposition between Nature and Culture) is the starting point of any classification, of any classificatory order, that opens up, with its articulations, the realm of the sacred. 